\title{
A Learning Model based on Comprehensive Games (Study on Conceptual Learning Model to Improve Early Childhood Abilities)
}

\author{
Sri Tatminingsih
}

Early Childhood Education Program, Faculty of Teacher Training and Education, Jakarta, Indonesia, tatmi@ecampus.ut.ac.id

\begin{abstract}
Learning or development activities in early childhood should be implemented holistically and comprehensively to develop all aspects of its development, including cognitive and emotional social. One of the models developed is a comprehensive game-based learning model. This early childhood learning model was developed through research and development with 9 (nine) steps developed by Borg and Gall. The model was developed with reference to three games: constructive, educational and traditional games based on learning theories of early childhood and the theories associated with the three games. This model is purposely designed for alternative members of early childhood teachers to stimulate Children's abilities. Stages in this model include 1) Conducting initial assessment 2) Analyzing initial ability 3) Implementing the learning process 4) conducting the final assessment 5) analyzing the final assessment result and all the stages are evaluated thoroughly. The materials and tools used in this model is: an assessment instrument of cognitive, social-emotional abilities, guides and a comprehensive game tool called "Colored Sticks", as well as an instrument of observation of learning. In this model, the role of Early Childhood Education teachers as facilitators, planners, implementers and assessors cannot be replaced.
\end{abstract}

Keywords: learning models; comprehensive games; early childhood; children's Abilities

\section{INTRODUCTION}

The kindergarten age is included in the early age, which is often referred to as the golden period in the life of a human being because at this time children have extraordinary potential that will be able to develop as well as possible if they get the right stimulation and become a strong foundation in further development if stimulated holistically early on [1]. This period is also referred to as a play period, because at this time they really like playing activities, even most of their day is filled with play activities. This has become the basis of development activities in kindergarten through play [2]. The results of stimulation carried out by educators (teachers and parents) will be optimal if the stimulation provided is based on the learning abilities of each child and the opportunities available [3], and done through fun play activities [4]. One of these activities is playing which is one of the activities in humans, which is a manifestation of habits, experiences, desires, creativity and results of thought and culture [5]. Therefore, educators in kindergarten should facilitate children with various activities and games.

There are many game tools in almost every kindergarten that teachers use to improve the development of children, both indoors and outdoors. Outdoor play equipment is typically used to stimulate the motor skills of a child, but this is not always the case [5,6], such as constructive play tools such as Lego, blocks, Lassy, bombiq and puzzles and educational play tools such as: building boxes, plasticine, and beads and game tools traditional such as: kalah, hoop, Chinese chequers, snakes and ladder, rubber band. These game tools are often used by kindergarten teachers to stimulate children's abilities such as children's cognitive and social emotional abilities. These game tools are often used by kindergarten teachers to stimulate children's abilities such as children's cognitive and social emotional abilities. The use of game tools is usually done separately and individually. For example, Lego are only used to develop cognitive skills, rubber bands are used to develop cooperation and perseverance. Therefore, in this article we will discuss learning models to develop children's abilities by combining three types of games, namely constructive, educative and traditional games comprehensively.

Comprehensive play is a game tool that combines constructive, educational and traditional games that are deliberately designed specifically for educational purposes that can actively involve children, are constructive and provide opportunities for children to develop their abilities effectively and systematically [7]. 


\section{THEORY}

a. School Readiness (Heading 2)

A kindergarten is basically one of the platforms that can help young children develop their school readiness [8]. School readiness is also a process of growing a child through various efforts from within the child and his environment so that they have readiness in pursuing education in formal institutions called schools [9]. The readiness which includes: social and emotional abilities, including turn-taking, communication, compassion, and the ability to express one's own emotions, experience in having a sense of self-worth, a positive attitude towards life and cooperative prosocial behavior [10, 8]; Learning strategies, including excitement, interest, personality, history, and values; Motor and physical well-being, including health status, growth and disability [8, 2, 11]; Language development, including listening, speaking, and vocabulary, as well as literacy skills, including print awareness, sense of story, and processes of writing and drawing [8, 11]; General knowledge and cognition, including sound-letter association, spatial relationships, and number concepts, logical thinking skill, problem solving, skills in make believe play and higher other thinking skill $[10,8,12$, 13] .

\section{b. The Comprehensive Game}

The comprehensive game in this study is a game that uses tools that will be developed by researchers. This game is a combination of three types of games, namely constructive games [2], educative games [14] dan tradisional games [15]. Comprehensive game in this context is a game that adopts a domino game. Adoption of the game includes: a) How to play is made easier and varied according to the abilities and development of children b) The shape of the card is replaced with wood whose size is adjusted to the size of the child's hand. c) The dots on the card are replaced with numbers, letters, geometric shapes and signs of addition and subtraction operations in mathematics with the difficulty level adjusted for the child's development. d) Wood is given basic colors such as: red, blue, yellow, black and white. e) The number of cards in which 28 cards are replaced with wood is 95 cards to be played with various variations [7].

\section{METHOD}

This study uses a development research design consisting of 9 stages. The research begins with research and collects initial information, identifies learning objectives, analyzes learning, analyzes learners and context, writes specific learning objectives, develops assessment instruments, develop learning strategies, selects and develops learning materials, designs. and conducting formative evaluations, and ending with revising learning [16]. The training assessment phases are conducted through four phases, namely a) expert testing conducted by five experts, namely experts in the field of early childhood education, language, methodology, educational design and learning media. b) the user test phase, conducted by eight kindergarten teachers from eight different kindergartens in South Jakarta c) Testing in small groups. This test is conducted in a kindergarten class with a teacher and 8 children. d) trials in large groups conducted on teachers with 14 children.

\section{RESULT AND DISCUSSION}

The comprehensive game-based learning model developed in this study includes conceptual models, procedural models and physical models. These three models are developed through a fairly long and systematic process, namely through the stages of research and development that refers to the model proposed by [16]. Overall, this comprehensive game-based learning model contains the following characteristics:

a. This model was developed with the aim of creating a child-centered learning process through play activities that are fun, interesting and systematic.

b. This model adopts an integrated, holistic and integrated learning process throughout the entire learning process.

c. This model is designed according to the needs of early childhood education, especially kindergarten (TK) through the identification of the needs and characteristics of age group B children.

d. This model has been tested both in terms of readability, effectiveness and compatibility with the development of children aged group $\mathrm{B}$, which is aged five to 6 years.

e. This model includes an assessment of children's abilities

f. Kindergarten teachers are actively involved in the planning, development and application process to the revision of the learning model developed.

g. The teacher's role as a facilitator in this model cannot be replaced by the developed game tool.

a. Conceptual Models

The conceptual model developed has been through a one-on-one formative evaluation process by experts and formative evaluation by learners. At the end of each evaluation, this model is revised according to the input provided. The first revision was made after being evaluated by five experts, namely early childhood education experts, instructional media experts, language experts, instructional methods experts and instructional design experts. The second revision was made after the revision 1 model was evaluated by learners or users, in this case carried out by eight kindergarten teachers who came from different kindergartens around South Jakarta. The final conceptual based conceptual learning model produced is described as follows.

In the model it appears that the learning process begins with an initial assessment of abilities of children. This assessment is carried out individually using the assessment instrument. The result is called the child's initial ability. The application of this comprehensive game-based learning involves children and the role of the teacher. The learning process uses a Color Stick game which is a combination of constructive, educational and traditional games. In its application the teacher must study the guidelines that accompany this model. The learning process is carried out within a certain period, according to the design prepared by the teacher. At the end of the learning process a final assessment of their cognitive and social-emotional abilities is carried out. The results of the assessment are learning outcomes in the form of final cognitive and social-emotional 
abilities. The whole learning process is periodically evaluated by the head of kindergarten or the teacher appointed by the head of kindergarten.

This comprehensive game-based learning model is included in the behavioral system group learning model [17]. This model is included in the Behavioral Systems Model group, focusing on observable behavior. This model moves from the psychology of behaviorism, this group teaching model emphasizes the creation of a learning environment system that allows manipulation of reinforcing desired behavioral patterns. The creation of the environment is carried out by using game tools that are intentionally created so as to enable the manipulation of reinforcement of expected behavior patterns, namely the achievement of competencies expected of students. The application of this learning model is carried out while still emphasizing the principles of learning in early childhood, namely the principles of development-oriented learning, especially children in kindergarten. The principles of learning can be identified from several dimensions of learning concerned, including the creation of a learning climate, The principles of learning can be identified from several dimensions of learning concerned, including the creation of a learning climate, the environment and schedule of activities, learning experiences, learning strategies, motivation and guidance, curriculum and assessment system.

b. Physical Model

In this model created a game tools that includes:

1) Comprehensive Game Tools

A comprehensive game tool called Colored Sticks are a tool created by combining constructive, educative and traditional games. The process and results of making this tool prioritize security and safety for children when playing. This security starts from the material, how making it and its use. This tool is also designed so that children can play actively, independently and creatively. This game tool resembles the shape of a domino and is made of wood. The concepts include: shape, color, number, letter, size, classification and sequence [12].

2) Teacher's Guide in the Application of Colored Sticks in Kindergarten

This guide is a reference for teachers or related parties who will implement comprehensive game-based learning in kindergarten children. It is expected that after studying this guide the teacher can apply comprehensive game-based learning well and systematically so that the expected competence in children. This guide is packaged in 3 parts. The first part, namely the introduction, contains: background, objectives, scope and learning experiences that must be possessed by the teacher. The second part about the Comprehensive game which includes: Color stick tool form, concepts and abilities of children developed. The third part, the learning strategy and appendix in the form of examples and the format and assessment instruments used

\section{CONCLUSION AND RECOMMENDATION}

This comprehensive game-based learning model is one alternative learning that can be applied to early childhood education, especially in kindergartens. The process contained in this learning model if implemented correctly in accordance with the guidelines it will be able to help educators stimulate children's readiness to study at the level of formal education or school readiness. This learning model has a set of game tools whose use will be more effective if guided by a teacher. The meaning is that this model cannot replace the role of the teacher in the classroom.

The recommendation for educators is that the educator needs to study the guidelines and try the game first so that the application will be effective and systematic. In addition, educators must also have creativity and be responsible in choosing and using the right strategies when applying this learning model. In addition, each educator can develop learning materials needed in accordance with the situations and conditions contained in the school environment

\section{REFERENCES}

[1] Londoño, et.al, "Early Childhood Development and Education: Theoretical Convergences and Divergences," International Education Studies; Vol. 12, No. 7. doi:10.5539/ies.v12n7p1, pp. 1-9, 2019.

[2] E. B. Hurlock, Child Development 6th Ed, Tokyo: McGraw Hill Inc.International Student Ed., 2007.

[3] Dolgova, et.al., "Early Childhood Educator Professional Development," in The European Proceedings of 18th PCSF 2018: Professional Culture of the Specialist of the Future, UK, 2018.

[4] E. Rogulj, Prikaz knjige: The SAGE handbook of Outdoor Play and Learning, Zagreb: Faculty of Teacher Education, University of Zagreb, Savska cesta 77, 2018

[5] Kolb and Kolb, "Learning to play, playing to learn: A case study of a ludic learning space," Journal of Organizational Change Management Vol. 23 No. 1, DOI 10.1108/09534811011017199, pp. 26-50, 2010.

[6] Lindberg and Laine, "Detecting Play and Learning Styles for Adaptive Educational Games," Department of Information and Computer Engineering, Ajou University, Suwon, South Korea DOI: 10.5220/0005858501810189, pp. 1-9, 2017.

[7] S. Tatminingsih, "Coloured Stick: Teaching with a comprehensive game for improving children's social-emotional ability in kindergarden," Különleges Bánásmód, 5. (1). DOI 10.18458/KB, p. 
59-65, 2019.

[8] P. C. High, "School Readiness," American Academic of Pediatrics Volume 121, Number 4, DOI: 10.1542/peds.2008-0079, pp. 1008-1015, 2015.

[9] Ayoub and Bartlett, Family engagement and school readiness, USA: The National Center on Parent, Family, and Community Engagement., 2015.

[10] Dodge, Diane T and Colker, Laura J , The Creative curriculum for Early Chilhood., Washington: Teaching Strategies. Inc. , 2001.

[11] D. E. Papalia, A Child's World, New York: McGraw-Hills Publishing Company, 1995.

[12] G. W. Maxim, The very Young: Guiding Children from Infancy Through the Early Years, New York: McMillan Publishing Co., 1993.

[13] Tatminingsih, "Alternatif Stimulasi Kemampuan Kognitif melalui Penerapan Model Pembelajaran Berbasis Permainan Komprehensif," Jurnal Obsesi: Jurnal Pendidikan Anak USia Dini Vol 3, No 1 (2019)

DOI: https://doi.org/10.31004/obsesi.v3i1.130, pp. 183190, 2019.

[14] M. S. Tedjasaputra, Bermain, Mainan dan Permainan untuk Pendidikan Usia Dini, Jakarta: Grasindo, 2001.

[15] J. Danandjaya, Folkfore Indonesia, Jakarta: Gramedia, 1987.

[16] Borg and Gall, Educational Research: An Introduction, New York: Pitman PublishingInc. , 2007.

[17] Calhoun, et. al, Models of Teaching (Edisi delapan), Yogyakarta: Pustaka pelajar, 2009. 